\title{
Ensinar ciências na perspectiva da sustentabilidade: barreiras e dificuldades reveladas por professores de biologia em formação
}

\section{Teaching science in the perspective of sustainability: barriers and difficulties revealed by biology teachers in training}

\author{
Magnólia Fernandes Florêncio de Araújo ${ }^{1}$ \\ Maria Arminda Pedrosa ${ }^{2}$
}

\begin{abstract}
RESUMO
A presente investigação parte de uma visão global sobre as dificuldades relativas ao ensino de biologia na perspectiva do desenvolvimento sustentável e da formação de professores dessa área para atuarem no ensino básico. Tem como objetivo identificar os temas relacionados ao ambiente e ao desenvolvimento sustentável que são considerados difíceis de serem ensinados, caracterizando os motivos dessas dificuldades. A pesquisa se desenvolveu numa abordagem qualitativa e quantitativa. De forma geral, identificou-se que os participantes da pesquisa indicam dificuldades em incluir questões sobre desenvolvimento sustentável em suas futuras aulas e que a ausência da abordagem multidisciplinar ou interdisciplinar corresponde a uma razão importante para as dificuldades em ensinar na perspectiva da sustentabilidade, uma vez que isso possibilitaria aos alunos fazer uma análise do ambiente do ponto de vista das dimensões sociais e econômicas, além de poderem avaliar os aspectos éticos a elas relacionados.
\end{abstract}

Palavras-chave: ensino de ciências; sustentabilidade; dificuldades de ensinar.

DOI: $10.1590 / 0104-4060.35890$

1 Universidade Federal do Rio Grande do Norte. Natal, Rio Grande do Norte, Brasil. Campus Universitário. BR 101. Lagoa Nova. CEP: 59097-072.

2 Universidade de Coimbra. Faculdade de Ciências e Tecnologia, Polo II. Coimbra, Portugal. Rua Sílvio Lima. CEP: 3030-790. 


\begin{abstract}
This research is part of an overview of the difficulties related to biology education in the perspective of sustainable development and teacher training in this area to work in basic education. It aims to identify the issues related to environment and sustainable development which are considered hard to be taught, characterizing the reasons for such difficulties. The research has been developed in a qualitative and quantitative approach. Overall, we found that the survey participants indicate problems to include matters on sustainable development in their future classes and that the absence of a multidisciplinary or interdisciplinary approach represents an important reason for the difficulties in teaching from the perspective of sustainability, since this would enable students to analyze the environment from the point of view of social and economic dimensions, in addition to assessing the ethical aspects related to them.
\end{abstract}

Keywords: science teaching; sustainability; teaching difficulties.

\title{
Introdução
}

Embora reconheçamos que a educação não vá resolver os grandes problemas ambientais do planeta, não há como negar que ela pode ser um caminho interessante para a divulgação de ideias que visem contribuir para o alcance de um mundo melhor e mais justo para todos, a partir de ações concretas que procuremos realizar no planeta. No Brasil, as discussões desta natureza apresentadas no âmbito dos Parâmetros Curriculares Nacionais (PCNs) associam-se a outras iniciativas semelhantes, uma vez que essas questões são planetárias, não sendo relativas a países específicos. Assim, ensinar ciências numa perspectiva de formação para a cidadania e para a sustentabilidade se torna relevante, podendo se refletir em educadores com uma formação que lhes permita interferir positivamente na qualidade de vida das pessoas e do planeta.

Atualmente, há uma tendência geral das sociedades ocidentais na perspectiva de alteração do modo como é trabalhada a educação científica, passando-se a considerar o reconhecimento social e político do papel das ciências e das tecnologias. A formação geral do cidadão tem estado cada vez mais em pauta, com a perspectiva de que a educação científica seja promotora de igualdade, justiça social, diversidade e sustentabilidade ambiental.

Nesse contexto, as relações entre Ciência, Tecnologia e Sociedade caracterizam-se por uma nova postura educativa, implicando a seleção de conteúdos 
menos tradicionais, e partindo de situações vinculadas aos contextos da sociedade atual. Além disso, as metodologias de ensino devem permitir a participação ativa dos alunos, com o estímulo de debates e apresentação de opiniões, numa postura crítica frente à participação da Ciência e da Tecnologia na Sociedade, o que poderá contribuir para a transformação social e, assim, para uma vida melhor.

Para a UNESCO 3 , o grande desafio para o Brasil está em "fazer com que os investimentos realizados no ensino de ciências cheguem cada vez mais de forma homogênea à população e possam efetivamente melhorar a sua qualidade de vida”. Pedrosa (2012) questiona o que seria necessário, em sistemas formais de educação, nos dias atuais, para auxiliar os estudantes a desenvolverem uma cidadania na perspectiva do desenvolvimento sustentável. Quais seriam as políticas e em que níveis elas deveriam ser implementadas? Em termos práticos, nas escolas, salas de aulas e laboratórios, o que poderia ser feito?

\section{Importância da Educação em Biologia}

Os Parâmetros Curriculares Nacionais destacam que "Dominar conhecimentos biológicos para compreender os debates contemporâneos e deles participar" constitui apenas uma das finalidades do estudo da Biologia como ciência, no âmbito escolar. De acordo com esse documento, as ciências biológicas reúnem algumas das respostas às indagações que vêm sendo formuladas pelo ser humano, ao longo de sua história, para compreender a origem, a reprodução, a evolução da vida e da vida humana em toda sua diversidade de organização e interação. Representam também uma maneira de enfrentar as questões com sentido prático que a humanidade tem enfrentado, desde sempre, visando à manutenção de sua própria existência e que dizem respeito à saúde e à produção de alimentos, só para exemplificar. Devemos compreender, entretanto, que a biologia é uma área complexa, e que apresenta situações que constituem a realidade da vida de cada ser humano, o que torna fundamental o papel da Educação Biológica na formação de uma cidadania responsável.

O conhecimento escolar da biologia permite que se amplie a compreensão dos seres vivos, contribuindo para que seja percebida a singularidade da vida humana relativamente aos demais organismos, em função de sua incomparável capacidade de intervenção no meio. $\mathrm{O}$ fato de a vida ser o tema central na edu-

$3<$ http://www.unesco.org/new/pt/brasilia/natural-sciences/science-and-technology/scienceeducation/>. 
cação biológica a torna um recurso privilegiado para o enfrentamento de muitas questões humanas, incluindo as ambientais, auxiliando na conscientização das futuras gerações e contribuindo para a superação desses problemas e o alcance de um mundo melhor para todos. Assim, aprender os fenômenos biológicos, os seres vivos, o corpo e a sexualidade, a saúde e os usos, pela sociedade, dos produtos científicos e dos recursos tecnológicos deveriam permitir o desenvolvimento de capacidades específicas para compreender a história evolutiva dos seres vivos, caracterizar a diversidade da vida no planeta, reconhecer situações de desequilíbrio ambiental, avaliar a eficácia de métodos de intervenção, reconhecer a importância de se conservar o meio. Ampliam também suas capacidades de valorizar os cuidados com o próprio corpo, de entender que boas condições de moradia, saneamento, trabalho, transporte, lazer e alimentação são essenciais para o bem-estar de todos nós.

\section{Temas de difícil ensino e aprendizagem em Educação biológica}

Os conceitos biológicos são, reconhecidamente, fontes de muitas das dificuldades apresentadas pelos alunos, o que deveria servir de incentivo para que os professores busquem novas formas de organizar e abordar o conteúdo, de modo que ele esteja adaptado aos interesses e capacidades dos aprendizes. Como algumas dessas dificuldades ocorrem devido às deficiências que os próprios professores apresentam em trabalhar os conteúdos, refletindo na má compreensão dos alunos, utilizar materiais potencialmente interessantes tem como consequência uma maior contribuição para a aprendizagem significativa dos discentes e a redução das dificuldades de aprendizagem existentes.

Outros fatores constatados são a inadequação da explicação de alguns conceitos pelo professor; o curto tempo para exposição dos conceitos; a dificuldade do professor em responder às dúvidas dos alunos; a falta de discussão sobre determinados aspectos considerados importantes para ancorar o novo conhecimento; a grande quantidade de termos novos dos quais os alunos precisam se apropriar e a falta de atividades práticas ou experimentais para auxiliar na exposição do conteúdo, dentre outros fatores.

Sabe-se, por outro lado, que outras tantas dificuldades são próprias da natureza do conteúdo. No caso de conteúdos que exijam uma compreensão em um nível microscópico, por exemplo, esse fato é caracterizado pela natureza abstrata e complexa dos conceitos, os quais revelam estruturas microscópicas e compostos que não podem ser visualizados a olho nu, como por exemplo o 
DNA, as proteínas e os genes (BAHAR et al., 1999; RIEMEIER; GROPENGIEßER, 2008).

Várias pesquisas em educação científica apontam que uma das áreas de conteúdo mais difícil de aprender, em ciências, é a genética (LEWIS; WOOD-ROBINSON, 2000; BANET; AYUSO, 1995; HAAMBOKOMA, 2007; TOPÇU; PAHÝN-PEKMEZ, 2009; BOUJEMAA et al., 2010). A razão disso pode ter base no fato de que, para os alunos, é naturalmente difícil compreender conceitos que se referem ao que é invisível e intocável, como é o caso dos conceitos de genética (HAAMBOKOMA, 2007).

Outros dois temas considerados difíceis de aprender são respiração e fotossíntese (ROSS et al., 2006). Devido à sua natureza abstrata, esses conteúdos correspondem a temas considerados difíceis tanto para se ensinar quanto para se aprender em todos os níveis de escolaridade. De outra sorte, eles constituem um prerrequisito fundamental para o estudo da ecologia, por exemplo, o que permitiria, em um nível mais amplo, uma maior compreensão dos conceitos de sustentabilidade ambiental e mesmo uma ação mais cidadã, sendo estes, a fotossíntese e a respiração, temas que têm mesmo um papel central para os sistemas vivos.

Outra razão para se explicar essa dificuldade pode estar no caráter interdisciplinar desses conceitos, pois para compreender adequadamente esses temas, os alunos já devem dominar os conceitos de reações químicas, moléculas orgânicas e inorgânicas, a fim de compreenderem a natureza química da respiração e da fotossíntese, fato que muitas vezes não ocorre. Para além disso, estudos realizados mostram que os alunos têm diversas concepções alternativas sobre as plantas (KOSE, 2008) e que têm dificuldade em compreender temas da biologia ligados ao corpo humano, como os órgãos internos, os sistemas orgânicos e o seu funcionamento. Esses estudos mostram que os sistemas orgânicos de menor compreensão são o sistema digestivo, o respiratório e o esquelético, além do sistema excretor (TEKKAYA et al., 2001). O entendimento deste conceito depende de conhecimentos prévios sobre os processos de osmose e difusão, os quais já devem ter sido estudados pelos alunos na série anterior pra que sejam melhor incorporados ao serem relacionados a outros temas.

De maneira especial, as funções do sistema nervoso compreendem outro tópico, o qual os alunos sentem dificuldades em compreender. Quanto ao sistema circulatório, os conceitos de pressão e velocidade do sangue são pouco compreendidos, bem como é difícil entender o papel da difusão como um dos principais mecanismos de troca de materiais por meio dos capilares. Além disso, a falta de integração do estudo dos hormônios com os sistemas faz com que este tema seja aprendido apenas por memorização, dificultando a compreensão do seu papel. 
Estudo desenvolvido por Cardak (2009) mostra que muitos alunos do nível universitário, em preparação para ensinar ciências, ou seja, futuros professores da área, também apresentam concepções alternativas em relação à classificação dos animais. Esses estudos, em grande parte, referem-se a trabalhos realizados em outros países, sendo fundamental que sejam desenvolvidos também aqui no Brasil, como forma de evidenciar que essas dificuldades independem de condições econômicas, culturais ou sociais.

Ainda é pequeno o foco sobre a Educação para o desenvolvimento Sustentável (EDS) na formação inicial de professores de ciências, e os projetos e iniciativas desenvolvidas nas escolas, nessa perspectiva, ainda são escassos.

Pouco se sabe, também, sobre as dificuldades dos professores em relação a esses temas, a eficácia das suas investidas pedagógicas para o desenvolvimento da aprendizagem dos seus alunos e, sobretudo, o desenvolvimento de seus próprios conceitos e valores em relação à educação para a sustentabilidade como resultado desse processo. Borg et al. (2012) chamam atenção para o fato de que o desenvolvimento sustentável é uma questão controversa porque existem percepções diferentes dentro do debate ambiental e conflitos de interesse, uma vez que diferentes grupos da sociedade percebem e consideram fenômenos ambientais de formas diferenciadas. Esses autores investigaram os obstáculos que professores enfrentam para darem aulas na perspectiva EDS e se havia diferenças, dependendo da disciplina, concluindo que os currículos criam dificuldades, por impedirem a interdisciplinaridade, mantendo professores presos às suas áreas específicas. Além disso, muitos estudos apontam que o estudo da diversidade biológica, de modo geral, e os ciclos da matéria no planeta são caracteristicamente difíceis (ÇIMER, 2012).

Em pesquisa realizada em diversas escolas americanas, Shepardson et al. (2011) observaram que os estudantes apresentaram concepções semelhantes a outras já citadas na literatura em relação ao efeito estufa, aquecimento global e mudanças climáticas, as quais apresentavam confusões conceituais. Isso demonstra que lidar com esses conteúdos complexos e, sob muitos aspectos, abstratos, não é trivial.

A partir dessa visão global sobre as dificuldades relativas ao ensino de biologia na perspectiva do desenvolvimento sustentável, e considerando a formação de professores de biologia para atuarem no ensino básico, os objetivos desta investigação foram identificar os temas relacionados ao ambiente e ao desenvolvimento sustentável, em especial, considerados por professores de biologia em formação, difíceis de serem ensinados e caracterizar os motivos dessas dificuldades. 


\section{Metodologia da investigação}

A pesquisa se desenvolveu numa abordagem qualitativa e quantitativa e, tendo em conta os objetivos da pesquisa, são apresentados, nesta seção, os aspectos metodológicos fundamentais, designadamente a caracterização da amostra, do instrumento de coleta de dados, e o modo como foram analisados os dados recolhidos.

\section{A amostra}

Colaboraram com esta investigação 121 estudantes do curso de licenciatura em ciências biológicas da Universidade Federal do Rio Grande do Norte, que foram convidados a participar, assinaram um termo de consentimento livre e esclarecido e autorizaram as pesquisadoras a utilizar as suas respostas em publicações. Todos os alunos eram concluintes ou estavam finalizando o terceiro ano do curso, já tendo, portanto, cumprido a maioria da sua carga horária de formação.

\section{O instrumento de coleta de dados}

Um questionário compreendendo diversos aspectos relacionados com desenvolvimento sustentável foi o instrumento utilizado na investigação. Neste trabalho, entretanto, tratar-se-á apenas daquilo que se refere a temas ambientais considerados difíceis de ensinar, em especial o desenvolvimento sustentável. Para isso, foram selecionadas, no questionário aplicado, duas questões abertas, quais sejam:

Questão 1: Estando em formação para ensinar Ciências e Biologia, considera dificil trabalhar ideias de desenvolvimento sustentável?

\section{( ) Sim ( ) Não ( ) Não sei}

Por quê?

Questão 2: Considerando sua futura prática docente, quais os temas das Ciências Biológicas que considera envolverem conceitos ambientais mais difíceis de ensinar? 
É importante ressaltar que as questões formuladas foram, inicialmente, submetidas à revisão de três especialistas da área e de 10 alunos de pós-graduação, tendo sofrido algumas modificações resultantes das sugestões recolhidas.

\section{A análise dos dados}

As respostas às questões discursivas foram analisadas com base na Técnica de Elaboração e Análise de Unidades de Significado, uma técnica de investigação qualitativa, originária da combinação de outras abordagens (MOREIRA et al., 2005). As etapas envolvem a análise do Relato ingênuo, que corresponde à leitura do que o respondente escreve na sua forma exata, sem modificações, seguida da Identificação de atitudes em que se procura ter uma visão do todo, separando-se as unidades mais significativas para a criação de indicadores e categorias que referenciem a interpretação e, por fim, a Interpretação, que se dá após estar montado o quadro geral das ideias de cada sujeito, bem como as convergências e divergências identificadas. Nesta etapa, faz-se uma análise interpretativa do fenômeno, buscando compreendê-lo na sua essência, a partir de pressupostos teóricos sobre o tema.

A análise envolveu a simples contagem dos números de respostas por categorias que emergiram das análises, e as percentagens desses dados foram calculadas.

\section{Resultados e discussão}

Questionados sobre se consideravam que seria difícil trabalhar ideias sobre desenvolvimento sustentável, a maioria dos professores em formação (63\%) respondeu que sim, e ainda $16 \%$ disseram que não sabiam ou não responderam. Apenas 21\% disse que não achava difícil (Figura 1).

Os motivos apresentados pela grande maioria que afirmou ser difícil ensinar na perspectiva de desenvolvimento sustentável estão categorizados no Quadro 1, a seguir: 


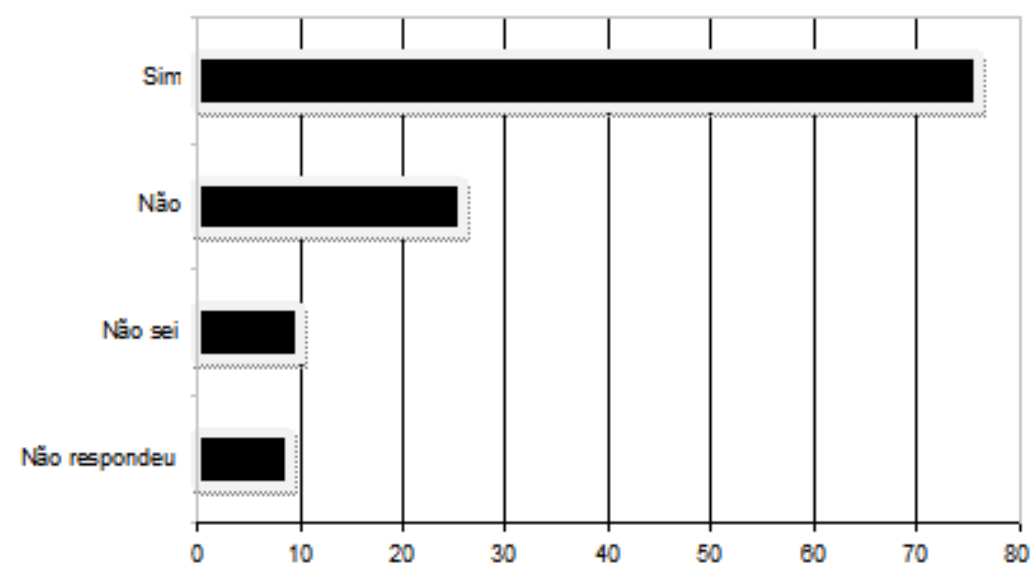

FIGURA 1 - RESPOSTAS À QUESTÃO: "ESTANDO EM FORMAČ̃O PARA ENSINAR CIÊNCIAS E BIOLOGIA, CONSIDERA DIFÍCIL TRABALHAR IDEIAS DE DESENVOLVIMENTO SUSTENTAVEL?"

Fonte: Este estudo. $\mathrm{N}=121$.

\begin{tabular}{|l|c|}
\hline $\begin{array}{l}\text { Explicações dadas para as dificuldades em ensinar na } \\
\text { perspectiva da sustentabilidade }\end{array}$ & $\begin{array}{c}\text { Número de respostas } \\
\text { relacionadas/ } \\
\text { percentagem }\end{array}$ \\
\hline É dificil mudar cultura, costumes e valores de uma sociedade. & $15-27 \%$ \\
\hline $\begin{array}{l}\text { Exige conhecimentos sobre várias áreas (ecologia, política, } \\
\text { economia, educação) e o professor não é qualificado pra isso. }\end{array}$ & $13-24 \%$ \\
\hline $\begin{array}{l}\text { É difícil conscientizar as pessoas sobre as questões } \\
\text { ambientais. }\end{array}$ & $10-18 \%$ \\
\hline $\begin{array}{l}\text { Envolve conhecimentos novos, que exigem rupturas com } \\
\text { conceitos antigos (dos alunos). }\end{array}$ & $5-9 \%$ \\
\hline $\begin{array}{l}\text { Há visões e realidades diferentes sobre os usos dos recursos: } \\
\text { o tema é polêmico. }\end{array}$ & $2-4 \%$ \\
\hline Os temas são complexos e contraditórios. & $2-4 \%$ \\
\hline Há concepções alternativas sobre isso e é difícil mudá-las. & $2-4 \%$ \\
\hline $\begin{array}{l}\text { O professor não desenvolve esses temas de maneira a atrair o } \\
\text { interesse dos alunos. }\end{array}$ & $1-2 \%$ \\
\hline O livro didático não traz esse tema. & $5 \%$ \\
\hline
\end{tabular}

QUADRO 1 - MOTIVOS INDICADOS PELOS ENTREVISTADOS PARA AS DIFICULDADES DE ENSINAR BIOLOGIA NA PERSPECTIVA DO DESENVOLVIMENTO SUSTENTÁVEL

FONTE: Este estudo. 
De forma geral, identifica-se que os participantes da pesquisa compreendem que será difícil incluir questões sobre desenvolvimento sustentável em suas futuras aulas. $\mathrm{O}$ maior obstáculo, segundo os dados, deve-se à dificuldade de serem mudados os costumes e valores das pessoas, opinião que é corroborada por outros estudos (BORG et al., 2012), assim como o aspecto multidisciplinar ou interdisciplinar que, do ponto de vista dos professores em formação, torna difícil ensinar com o caráter da sustentabilidade. Barthes et al. (2013) também entendem que a interdisciplinaridade permite que os estudantes analisem o ambiente do ponto de vista das dimensões sociais e econômicas, além de poderem avaliar os aspectos éticos a elas relacionados, embora essa visão não seja consensual (BORG et al., 2012). Isso facilitaria, ao professor, lidar com essas questões.

As explicações dadas por aqueles que disseram que não há dificuldades de ensinar na perspectiva do desenvolvimento sustentável estão expressas no quadro a seguir:

\begin{tabular}{|l|c|}
\hline $\begin{array}{l}\text { Explicações dadas pelos que não acham difícil } \\
\text { ensinar na perspectiva da sustentabilidade }\end{array}$ & $\begin{array}{c}\text { Número de respostas } \\
\text { relacionadas/percentagem }\end{array}$ \\
\hline É um tema atual e muito divulgado pela mídia. & $8-35 \%$ \\
\hline É um tema do cotidiano. & $4-17 \%$ \\
\hline É um tema amplo. & $4-17 \%$ \\
\hline $\begin{array}{l}\text { Um bom planejamento e uma boa ideia já permitem } \\
\text { tratar o tema. }\end{array}$ & $4-17 \%$ \\
\hline Envolve questões simples e interessantes de trabalhar. & $3-17 \%$ \\
\hline
\end{tabular}

QUADRO 2 - MOTIVOS INDICADOS PELOS ENTREVISTADOS PARA A FACILIDADE DE ENSINAR BIOLOGIA NA PERSPECTIVA DE DESENVOLVIMENTO SUSTENTÁVEL

FONTE: Este estudo.

Para quem considera fácil ensinar sob esse enfoque, a mídia seria uma aliada, por trazer os temas à tona, divulgando-os. $\mathrm{O}$ fato de serem assuntos amplos e relativos ao cotidiano também foram apontados como motivos para isso. Percebe-se, assim, que um pequeno percentual dentre os licenciandos entrevistados não destaca a complexidade do tema ou a falta de formação como empecilho para discuti-lo, o que poderá se refletir em um tratamento superficial. Isso tem uma implicação sobre a necessidade de que, na formação do professor, ele deva ser despertado a perceber não apenas quais são os principais problemas ambientais enfrentados hoje, mas também o modo como isso afeta a capacidade do planeta de dar suporte à vida, e que saídas ele poderá discutir com seus alunos, na perspectiva de mitigação desses problemas (JENSEN, 2008). 
Quando solicitados a apontarem temas ambientais mais difíceis de ensinar, a maioria das respostas se referiu à poluição ou a problemas ambientais em termos genéricos, além da própria sustentabilidade (Quadro 3).

\begin{tabular}{|c|c|c|}
\hline $\begin{array}{l}\text { Tema identificado como difícil } \\
\text { de ensinar }\end{array}$ & Motivos & $\begin{array}{c}\text { Respostas } \\
\text { relacionadas/ } \\
\text { Percentagem }\end{array}$ \\
\hline $\begin{array}{l}\text { Poluição/poluentes/ } \\
\text { problemas ambientais }\end{array}$ & $\begin{array}{l}\text { Dificuldade de orientar; relação } \\
\text { com química, pelo costume de } \\
\text { viver em ambiente poluído; as } \\
\text { pessoas se preocupam pouco. }\end{array}$ & $18-31 \%$ \\
\hline Sustentabilidade & $\begin{array}{l}\text { Mudar a } \quad \text { cultura } \quad \text { da } \\
\text { superexploração } \\
\begin{array}{l}\text { conceitos } \\
\text { ena }\end{array} \\
\text { díficeis. }\end{array}$ & $13-22 \%$ \\
\hline $\begin{array}{l}\text { Grandes problemas ambientais: } \\
\text { Camada de ozônio/ aquecimento } \\
\text { global/ Efeito estufa }\end{array}$ & $\begin{array}{l}\text { Envolve química; tem } \\
\text { controvérsias; é extenso e } \\
\text { complexo. }\end{array}$ & $11-19 \%$ \\
\hline $\begin{array}{l}\text { Uso correto/racional da água e } \\
\text { do solo }\end{array}$ & $\begin{array}{l}\text { Cultura do desperdício } \\
\text { enraizada; falta de educação; } \\
\text { forma inadequada de utilização. }\end{array}$ & $8-14 \%$ \\
\hline Lixo/coleta seletiva/Reciclagem & $\begin{array}{l}\text { É dificil concientizar/convencer } \\
\text { as pessoas; resistência. }\end{array}$ & $7-12 \%$ \\
\hline Ciclos biogeoquímicos & $\begin{array}{l}\text { São muito complexos; falta de } \\
\text { qualificação do professor. }\end{array}$ & $7 \%$ \\
\hline Biodiversidade & Tema muito extenso & $7 \%$ \\
\hline $\begin{array}{l}\text { Desmatamento/rotação de } \\
\text { culturas/agricultura sustentável }\end{array}$ & Cultura das queimadas & $7 \%$ \\
\hline
\end{tabular}

QUADRO 3 - TEMAS AMBIENTAIS RELACIONADOS À SUSTENTABILIDADE MAIS DIFÍCEIS DE ENSINAR SEGUNDO OS PARTICIPANTES

FONTE: Este estudo.

As razões dadas para justificar as dificuldades em se ensinar muitos dos temas citados são ligadas a aspectos educacionais como a falta de qualificação do professor ou à complexidade conceitual própria do tema. Embora os participantes ressaltem os problemas ambientais como temas difíceis de serem ensinados, a relação entre o exercício da cidadania e a sensibilização a esses problemas, com os quais a sociedade contemporânea se confronta, não aparecem claramente como um motivo para isso. Também não são citados o crescimento demográfico ou os elevados níveis de consumo como obstáculos para se compreender melhor temas como o aquecimento global, o efeito estufa, o lixo ou o desmatamento. Sá e Martins (2005), em trabalho realizado com professores do ensino básico, também identificaram um menor reconhecimento em relação à variação do 
crescimento demográfico ao longo do tempo e à necessidade de estabilização da população mundial, em um diagnóstico das concepções de professores sobre ciência, cidadania e desenvolvimento sustentável.

\section{Considerações finais}

De forma geral, identifica-se que o aspecto multidisciplinar ou interdisciplinar corresponde a uma razão importante, do ponto de vista dos professores em formação, para as dificuldades em ensinar com o caráter da sustentabilidade, pois se entende que a interdisciplinaridade possibilita aos alunos fazer uma análise do ambiente do ponto de vista das dimensões sociais e econômicas, além de poderem avaliar os aspectos éticos a elas relacionados. Outros pontos que mereceram destaque, no trabalho, foram os aspectos culturais e a dificuldade de mudar o hábito das pessoas.

Novos estudos estão sendo conduzidos no sentido de compreender como se pode propor um enfoque que possibilite colaborar para uma educação em ciências que tenha como objetivo, também, educar para o desenvolvimento sustentável.

\section{REFERÊNCIAS}

BAHAR, M.; JOHNSTONE, A. H.; SUTCLIFFE, R. G. Investigation of students' cognitive structure in elementary genetics through word association tests. Journal of Biological Education, v. 33, p. 134-141, 1999.

BAHAR, M.; OZEL, M.; PROKOP, P.; USAK, M. Science Student Teachers' Ideas of the heart. Journal of Baltic Science Education, v.7, n. 2, p. 78-85, 2008.

BANET, E.; AYUSO, G. E. Introducción a la genética en la enseñanza secundaria y bachillerato: I. Contenidos de enseñanza y conocimientos de los alumnos. Enseñanza de las Ciencias, v.13, n. 2, p. 137-153, 1995.

BARTHES, A.; ALPE, Y; BADER, B. Questions and positions on education for sustainable development at university in France: example of short professional cycles. Environmental Education Research, v. 19, n. 3, p. 269-281, 2013.

BORG, C.; GERICKE, N.; OLOF HÖGLUND, H.; BERGMAN, E. The barriers encountered by teachers implementing education for sustainable development: discipline bound 
differences and teaching traditions. Research in Science \& Technological Education, v. 30, n. 2, p. 185-207, 2012.

BOUJEMAA, A.; PIERRE, C.; SABAH, S.; SALAHEDDINE, K.; JAMAL, C.; ABDELLATIF, C. University students' conceptions about the concept of gene: Interest of historical approach. US-China Education Review, v. 7, n. 2, p. 9-15, 2010.

BRASIL. Secretaria de Educação Fundamental. Parâmetros curriculares nacionais: Ciências Naturais. Brasília: Ministério da Educação e Secretaria de Educação Fundamental, 1998. Disponível em: <http://portal.mec.gov.br/seb/arquivos/pdf/ciencias.pdf>. Acesso em: 08/06/2011.

CARDAK, O. Science students' misconceptions about birds. Scientific Research and Essay, v. 4, n. 12, p. 1518-1522, 2009.

ÇIMER, A. What makes biology learning difficult and effective: Students' views. Educational Research and Reviews, v. 7, p. 61-71, 2012.

HAAMBOKOMA, C. Nature and causes of learning difficulties in genetics at high school level in Zambia. Journal of International Development and Cooperation, v. 13, n. 1, p. 1-9, 2007.

JENSEN, M. Learning about environmental issues with the aid of cognitive artefacts. SSKKII-publications Technical report 2008.01. p. 1-14, 2008.

KOSE, S. Diagnosing student misconceptions: using drawings as a research method. World Applied Sciences Journal, v. 3, n. 2, p. 283-293, 2008.

LEWIS, J.; LEACH, J.; WOOD-ROBINSON, C. All in the genes? - Young people's understanding of the nature of genes. Journal of Biological Education, v. 34, n. 2, p. 74-79, 2000.

MOREIRA, W. W.; SIMÕES, R.; PORTO, E. Content analysis: elaboration technique and signified units analysis. Revista Brasileira de Ciência e Movimento, Brasília, v. 13, n. 4, p. 107-114, 2005.

PEDROSA, M. A. An assessment of requirements to reframe science education towards education for sustainable development. In: GONÇALVES, F.; PEREIRA, R.; LEAL FILHO, W.; AZEITEIRO, U. M. (Eds). Environmental education, communication and sustainability. Frankfurt am Main, Peter Lang Publishers, v. 33, p. 71-97, 2012.

RIEMEIER, T.; GROPENGIEßER, H. On the roots of difficulties in learning about cell division: process-based analysis of students' conceptual development in teaching experiments. International Journal of Science Education, v. 30, n. 7, p. 923-939, 2008.

ROSS, P.; TRONSON, D.; RITCHIE, R. J. Modelling photosynthesis to increase conceptual understanding. Journal of Biological Education, v. 40, n. 2, p. 84-88, 2006.

SÁ, P.; MARTINS, I. Ciência, cidadania e desenvolvimento sustentável: concepções de professores do $1^{\circ}$ ciclo. Enseñanza de las Ciencias, n. Extra, VII Congresso, p. 1- 5, 2005. 
SHEPARDSON, D. P.; NIYOGI, D.; CHOI, S.; CHARUSOMBAT, U. Students' conceptions about the greenhouse effect, global warming, and climate change. Climatic Change, v. 104, p. 481-507, 2011.

TEKKAYA, C.; OZKAN, O.; SUNGUR, S. Biology concepts perceived as difficult by Turkish high school students. Science Education, v. 66, n. 4, p. 531-538, 2001.

TOPÇU, M. S.; PAHÝN-PEKMEZ; E. Turkish Middle School Students’ Difficulties in learning Genetics Concepts. Journal of Turkish Science Education, v. 6, n. 2, p. 55-62, 2009.

UNESCO. 2013. Disponível em: <http://www.unesco.org/new/pt/brasilia/naturalsciences/science-and-technology/science-education/>. Acesso em: 01/05/2013.

Texto recebido em 30 de março de 2014.

Texto aprovado em 06 de maio de 2014. 